\title{
Effects of ply orientation on nonlinear buckling of Aircraft composite stiffened panel
}

\author{
Ouadia Mouhat \\ Mohammed V University, Structure LGCE, EST Sale -CED of Mohammadia Engineering School, Rabat, Morocco. \\ Ouadie.moubat@gmail.com
}

\author{
Abdelmajid Bybi \\ Mohammed V University in Rabat, EST Sale - Morocco MEAT - Materials Energy Acoustics Team-CED of Mohammadia \\ Engineering School, Rabat.
}

\author{
Ahmed El Bouhmidi, Mohamed Rougui \\ Mohammed V University, Structure LGCE, EST Sale -CED of Mohammadia Engineering School, Rabat, Morocco.
}

\begin{abstract}
In this paper the demand for curved stiffened panels composite from carbon fiber reinforced plastics (CFRP) has emerged; these structures are most frequently used in aerospace engineering. Nearly $50 \%$ of the primary structure of the Boeing 787 is made up of woven graphite-epoxy. This research emphasizes the buckling analysis of stiffened composite panels using the nonlinear, finite element modelling. The stiffened panel is assumed to be subjected to a uniform axial compression load of $10 \mathrm{kN}$. For the nonlinear buckling analysis, a stiffened composite panel is made of carbon fibre composite (CFC) in epoxy, Kevlar in epoxy and E-glass (EG) in epoxy. Due to the fact that there are many stiffened composite panels materials, this paper therefore uses a numerical approach, to present the study and results of the nonlinear static buckling analysis of I-stiffened, on various composite panels. This research also presented the effect of the different ply orientations using Abaqus finite element analysis (FEA).
\end{abstract}

KEYwORDS. Stiffened composite panels; Nonlinear buckling analysis; FEM ply orientations.

\section{OPEN ACCESS}

Citation: Mouhat, O, Bybi, A., El Bouhmidi, A., Rougui, M., Effects of ply orientation on nonlinear buckling of aircraft composite stiffened panel, Frattura ed Integrità Strutturale, 50 (2019) 126-140.

Received: 22.06 .2019

Accepted: 29.07.2019

Published: 01.10.2019

Copyright: (C) 2019 This is an open access article under the terms of the CC-BY 4.0, which permits unrestricted use, distribution, and reproduction in any medium, provided the original author and source are credited.

\section{INTRODUCTION}

$\mathrm{T}$ he fuselage is the main part of the aircraft, which is made up of so many stiffened composite panels; the reinforced structures are made by arranging the members and frames in vertical, horizontal, diagonal and longitudinal directions. The study of fuselage sections is still very costly. This research is mainly focused on reinforced panels, considering the fact that there are two categories of the panel; considering the limit state, it is important more investigation was carried on this subject, so as to uncover greater findings, which is usually the 
impact of some research. Aircraft completion essentially depends on the capability of the structural panel materials to carry the total weight exerted by the internal components of the aircraft. Therefore, the fuselage structure of commercial aircraft is basically influenced by the interaction of its functions and its basic strength, rigidity, and durability. Manufacturing and designs must meet criteria stated above while considering the goals of low mass and cheaper structure for the future airplane. Similarly, if there is a wealth of metallic materials available to choose from, there are bollards to do intelligent design using metals. Several researchers are working on the replacement of metallic materials with other best performing materials. Therefore, composites are considered to be a superior choice for converting metallic structures in order to obtain a better power and weight, which ultimately translates into a better performance of aircraft.

The European aeronautical manufacturing industry is currently demand reduction in both the development and operating costs, by $20 \%$ and $50 \%$ in the short and long term, respectively. European Commission POSICOSS (EC), which continued from January 2000 to September 2004, is the project of regular quadrennial COCOMAT, which extended until September 2008, contributed to this goal [1-3].

Composite materials are particularly attractive for aeronautical and aerospace applications because of their exceptional strength/density ratio and superior physical properties [4].

Specifically, the applications of laminates (Multi-layered composite) have been much possible use in various aerospace fields [5].

Despite its wide application in the aerospace industry, laminates are generally missing in the normal direction of the fiber orientation angles. This due to their laminated form which consists of stacked interfaces with lower resistivity values.

The divergence between two layers can be explained by phenomenon called 'delamination' and it creates one of the most common modes of weakness in laminated composites. Delamination can dramatically reduce weight capacity and stability of the constituent materials, thereby increasing the chances of breakage [6]. Logically, the modeling of composite failure behavior has evolved as a primary goal in recent years [7-9].

Delamination is one of the most important factors in the layered composites for structures subjected to compressive loads, because, this is buckling will take place at the lower load level [10]. Manufacturing defects, collisions with birds, and instrument graves are some of the causes of delamination. Delamination mostly created to lateral shear and lateral shear at regular constraints; it is hard to sense this inter-laminar fracture due to the toughness of the CFRP composites [11]. However, There has been an increasing demand for a more precise and finite method of analysis as a result of recent and rapid development in computational analytical. When a laminate is under compression, the impact of delamination on stiffness and hardness can be determined by the pre-buckling load and post-buckling under submitted loads. Therefore, buckle mode is defined as the cracking mode in which the submitted structure has an abrupt failure due to delamination when subjected to compressive loading [12].

When the structure is subjected to axial compression loading, due to the design method, a short deformation will be created on the structure precisely when the load is at a critical level. As a result of the above condition, the structure will suddenly be subjected to severe deformation and as such, lack lifts which is in pre-buckling.

The authors argued that the presence of Nano-diamonds not only prevented the agglomeration of GO sheets but also acted as a fixing agent in the polymer composites, which could improve its breaking strength [13].

In the linear and non-linear buckling Analysis of stiffened panel composite is carried out in the pre-buckling; a detailed study is, therefore carried out to determine the buckling and post-buckling responses of stiffened panels composite with central circular defenses.

Subject to various combinations of mechanical and thermal loads, the results showed the effects of variations in hole diameter; the aspect ratio of the panel and the position of the fiber at the end of stability $[14,15]$. In real cases, the deviation continues even after subsequently taking the critical load, the post-buckling analysis is therefore non-linear, and by rule, the non-linear load traversal relationship can be taken from the non-linear stress.

Probably the most notable solution other than increasing the thickness of the plate could be to increase the stiffeners. Rigid panels are in principle, governed by the stability criterion of resistance. More details and reviews of the literature on laminated composite plates/shells may be found in Leissa A.W [16]. Empirical studies in rigid and composite non-rigid panels were carried out in [17]. In principle, with the advent of numerical methods FEM, many researchers around the world are currently working on designing the buckling attitude of the laminate through the FEM models. Sudhir Sastry et al. studied the buckling behavior of stranded laminated panels subjected to compression by applying a computational formation method [18].

Numerical methods for the modeling of composite laminates are not applicable in the design because the effect of several variables. The most structural design used in aerospace manufacturing is presented under the configuration of thin curved panels subjected to subject to compressive stresses. In the current study, we considered the buckling strength of the multi- 
layers for curved stiffened panel composite under the axial load of compression. Therefore, the layout of this work is presented in the following form:

$\checkmark$ Mathematical and numerical studies of nonlinear and linear buckle models.

$\checkmark$ Nonlinear buckling analysis.

$\checkmark$ Numerical study of the rigidity of the curved stiffened panels composites reinforced by the different configurations of combinations of the composites, the E-glass (EG) in epoxy and second composite is carbon fiber composite (CFC) in epoxy and finally with Kevlar in epoxy.

The analytical method for the design of laminated composite structures is not very useful from the practical point of view, because of the number of influencing parameters. Several applications of stiffened panels composites of the Aerospace manufacture in the form of rectangular composite structures subject to compression stress in longitudinal direction.

In this work, we have studied the critical load of static buckling of the composite stiffened panels subjected to a compressive load.

the work performed is the static analysis of buckling Introduced in the First Part of the theoretical mathematical computation and finite element analysis numerical buckling models are used in the second part the analysis of reinforced stiffened composite panels of (CFC) in epoxy, (EG) in epoxy and Kevlar in epoxy with several scenarios of layup sequences.

The main objective of this paper is to find the buckling load of stiffened composite panels is analyzed numerically through a nonlinear method formulation using Riks-Static option available in Abaqus.

Many researchers compared ply orientation in their work with method linear but in this work the compared ply orientation with method non-linear.

\section{BUCKLING ANALYSIS OF STIFFENED COMPOSITE PANELS}

7 he main aim of this study is to predict the linear and non-linear buckling behavior and resistance of an ideal linear and non-linear elastic structure. Which means that linear buckling analysis of a stiffened panel can be derived from the classic Euler method, which is not an exact solution when there are non-linear geometric material and there are any imperfections, moreover, nonlinear buckling analysis is a non-linear static analysis with gradually increasing loads to check the load level at which the structure becomes unstable. Therefore, the non-linear buckling analysis is more explicit and is recommended for design.

\section{Deformations and displacements of stiffened composite panels}

We considered a curved composite stiffened panel cross-section as shown in the Fig. 1 with a coordinate system and the displacement is shown in Fig. 2.

In this complementary study, we presented a formulation adapted for the stability analysis of the composite stiffened panel. The method using is the finite element method. The most important assumptions are linear elasticity, a fundamental way and the existence of critical loads. The formulation developed in this paper with energy is written as a sliding set of incremental coordinates. In the current paper, several finite element applications are used for buckling analysis.

Where $u, v$ et $w$ are the displacement vectors and $\theta_{x}, \theta_{y}$ et $\theta_{z}$ are the angles of rotation of a line perpendicular to the plane, along the direction $\mathrm{x}, \mathrm{y}$ and $\mathrm{z}$ respectively.

According to the theory of deformation by first-order stress, the displacement is given by the following system:

$$
\begin{aligned}
& u(x, y, z)=u_{0}(x, y)-z \theta_{x} \\
& v(x, y, z)=v_{0}(x, y)-z \theta_{y} \\
& w(x, y, z)=w_{0}(x, y)
\end{aligned}
$$

Where $\theta_{x}$ et $\theta_{y}$ the average rotations of a perpendicular line, within each element are can be expressed in terms of the unknown number of nodes using the following functions $N_{i}$ form: 


$$
\begin{aligned}
& u=\sum_{i=1}^{N} N_{i} u_{i}, \quad v=\sum_{i=1}^{N} N_{i} v_{i}, \quad w=\sum_{i=1}^{N} N_{i} w_{i} \\
& \theta_{x}=\sum_{i=1}^{N} N_{i} \theta_{x i}, \theta_{y}=\sum_{i=1}^{N} N_{i} \theta_{y i}, \theta_{z}=\sum_{i=1}^{N} N_{i} \theta_{z i}
\end{aligned}
$$

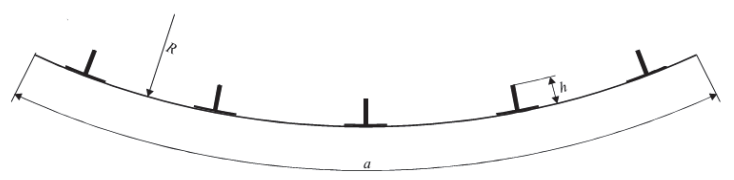

Figure 1: Panel cross-section

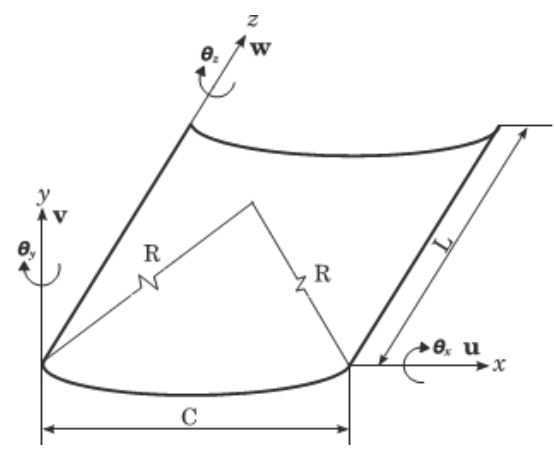

Figure 2: Coordinate System with the displacement

Where $N_{i}$ is the global number of nodes, the Lagrangian method is used in this work for each node, we define the response vector $q_{i}$ as:

$$
\left\{q_{i}\right\}=\left\{u_{i} v_{i} w_{i} \theta_{x_{i}} \theta_{y_{i}} \theta_{z_{i}}\right\}^{T}
$$

The total deformation is written in the following form:

$$
\begin{aligned}
& \{\varepsilon\}=\left\{\varepsilon_{0}\right\}+\left\{\varepsilon_{1}\right\} \\
& =\left\{\begin{array}{c}
u_{, x} \\
v_{, \mathrm{y}} \\
u_{, \mathrm{y}}+v_{, \mathrm{x}} \\
-\theta_{x, x} \\
-\theta_{\mathrm{y}, \mathrm{y}} \\
-\theta_{x, \mathrm{y}}-\theta_{\mathrm{y}, \mathrm{x}} \\
w_{, y}-\theta_{y} \\
w_{, \mathrm{x}}-\theta_{x} \\
\theta_{z}
\end{array}\right\}+\frac{1}{2}\left\{\begin{array}{c}
v_{, x}^{2}+w_{, \mathrm{x}}^{2} \\
u_{, \mathrm{y}}^{2}+w_{, \mathrm{y}}^{2} \\
2 w_{, x} w_{, y} \\
0 \\
0 \\
0 \\
0 \\
0 \\
0
\end{array}\right\}
\end{aligned}
$$

where

$$
\{\varepsilon\}=\left\{\varepsilon_{x} \varepsilon_{y} \gamma_{x y} \kappa_{x} \kappa_{y} \kappa_{x y} \gamma_{y z} \gamma_{z x} \theta_{z}\right\}^{T}
$$


Total potential energy of the panel

The total potential energy $\Pi$ is the summation of the strain energy $U$ and external load potential $\Omega$, expressed as follows:

$$
\begin{aligned}
& \Pi=U+\Omega \\
& \Pi=\frac{1}{2} \int\{\sigma\}^{T}\{\varepsilon\} d \Omega-\lambda\{q\}^{T}\{f\}
\end{aligned}
$$

$\lambda \mathrm{It}$ is assumed that the load factor to increment the load vector $\{f\}$ and stress vector $\{\sigma\}$ can be estimated from the right component:

$$
\{\sigma\}=\left\{N_{x} N_{y} N_{x y} M_{x} M_{y} M_{x y} Q_{x} Q_{y} M_{z}\right\}^{T}
$$

With $N_{x}, N_{y}$ and $N_{x y}$ are the stresses and $M_{x}, \mathrm{M}_{y}$ and $\mathrm{M}_{x y}$ are the moments, $Q_{x}$ and $\mathcal{Q}_{y}$ are the shear stresses, the characteristic law:

$$
\{\sigma\}=\{C\}\{\varepsilon\}
$$

Where $\mathrm{C}$ is the material constant matrix, the paper presents the evaluation of stresses and strains, deformations for static buckling analysis [19].

$$
\left\{\begin{array}{l}
N_{x} \\
N_{y} \\
N_{x y} \\
M_{x} \\
M_{y} \\
M_{x y} \\
Q_{y} \\
Q_{x} \\
M_{z}
\end{array}\right\}=\left[\begin{array}{lllllllll}
A_{11} & A_{12} & A_{16} & B_{11} & B_{12} & B_{16} & 0 & 0 & 0 \\
A_{12} & A_{22} & A_{26} & B_{12} & B_{22} & B_{26} & 0 & 0 & 0 \\
A_{16} & A_{26} & A_{66} & B_{16} & B_{26} & B_{66} & 0 & 0 & 0 \\
B_{11} & B_{12} & B_{16} & D_{11} & D_{12} & D_{16} & 0 & 0 & 0 \\
B_{12} & B_{22} & B_{26} & D_{12} & D_{22} & D_{26} & 0 & 0 & 0 \\
B_{16} & B_{26} & B_{66} & D_{16} & D_{26} & D_{66} & 0 & 0 & 0 \\
0 & 0 & 0 & 0 & 0 & 0 & A_{44} & A_{45} & 0 \\
0 & 0 & 0 & 0 & 0 & 0 & A_{45} & A_{55} & 0 \\
0 & 0 & 0 & 0 & 0 & 0 & 0 & 0 & C^{*}
\end{array}\right]\left\{\begin{array}{l}
\varepsilon_{x} \\
\varepsilon_{y} \\
\gamma_{x y} \\
\kappa_{x} \\
\kappa_{y} \\
\kappa_{x y} \\
\gamma_{y z} \\
\gamma_{z x} \\
\theta_{z}
\end{array}\right\}
$$

Where $A_{i j}, B_{i j}$ and $D_{i j}$ are stiffened panel properties using classical lamination theory (CLT) is a commonly used predictive tool, with $C^{*}$ correspond the stiffness values and $\theta_{z}$ in-plane rotation.

\section{The matrices for the stability analysis}

Analysis of linear static buckling at the beginning of the analysis, the stiffness matrix can be formulated as:

$$
\left[K_{0}\right]=\int_{\Omega}\left[B_{0}\right]^{T}[C]\left[B_{0}\right] \mathrm{d} \Omega
$$

Matrix $\left[B_{0}\right]$ used in reference [22] results of the Mindlin-Reissner hypothesis as a continuation: 


$$
\left[B_{0}\right]=\left[\begin{array}{cccccc}
\frac{\partial N_{i}}{\partial x} & 0 & 0 & 0 & 0 & 0 \\
0 & \frac{\partial N_{i}}{\partial y} & 0 & 0 & 0 & 0 \\
\frac{\partial N_{i}}{\partial y} & \frac{\partial N_{i}}{\partial x} & 0 & 0 & 0 & 0 \\
0 & 0 & 0 & -\frac{\partial N_{i}}{\partial x} & 0 & 0 \\
0 & 0 & 0 & 0 & -\frac{\partial N_{i}}{\partial y} & 0 \\
0 & 0 & 0 & -\frac{\partial N_{i}}{\partial y} & -\frac{\partial N_{i}}{\partial x} & 0 \\
0 & 0 & \frac{\partial N_{i}}{\partial y} & 0 & -N_{i} & 0 \\
0 & 0 & \frac{\partial N_{i}}{\partial x} & -N_{i} & 0 & 0 \\
0 & 0 & 0 & 0 & 0 & N_{i} \\
0 & & & & &
\end{array}\right]
$$

Matrix required for the stability analysis

The pre-buckling can be given by this precautionary measure:

$$
\left[K_{0}\right]\left\{q_{0}\right\}=\left\{f_{0}\right\}
$$

The second phase is the detection of critical states on the fundamental path reason, it is important to calculate the geometry of the stiffness matrix $\left[K_{\sigma}\right]$ this can be done as follows:

$$
\left[K_{\sigma}\right]=\int_{\Omega}[G]^{T}[\sigma][G] \mathrm{d} \Omega
$$

And matrix G, which is formed by:

$$
[G]=\frac{\partial N_{i}}{\partial x^{T}}
$$

Where $[\sigma]$ is the stress vector, stress reorganized in the form of a matrix according to Taylor [20].

$$
[\sigma]=\left[\begin{array}{cccc}
N_{y} & 0 & 0 & 0 \\
0 & N_{x} & 0 & 0 \\
0 & 0 & N_{x} & N_{x y} \\
0 & 0 & N_{x y} & N_{y}
\end{array}\right]
$$

The linear Eigenvalue problem is: 


$$
\left(\left[K_{0}\right]-\lambda\left[K_{\sigma}\right]\right)\{x\}=0
$$

The critical load is determined by Eqn. (16).

The static critical load is determined from Eqn. (16), the critical load $\lambda$ is corresponding to the eigenvector $\{x\}$.

Non-linear static buckling analysis

Non-linear static buckling usually involves several variables. These variables construct the stability equations and discrete equations of the virtual working equation:

$$
F^{N}\left(u^{M}\right)=0
$$

Either $F^{N}$ is the combined force component up to the $N^{\text {th }}$ level in the problem and $u^{M}$ is the value of the $M^{\text {th }}$ variable. The essential objective is the solution for an Eqn. (17).

Newton's method is supposed that after iteration $i$, an approximate $u_{i}^{M}$ of the solution was obtained as the exact solution of the discrete stability Eqn. (17), this shows that:

$$
F^{N}\left(u_{i}^{M}+c_{i+1}^{M}\right)=0
$$

With $c_{i+1}^{M}$ is the difference between this solution and the exact discrete result.

By lengthening the left side of this equation in a series of Taylor's:

$$
F^{N}\left(u_{i}^{M}\right)+\frac{\partial F^{N}}{\partial u^{P}}\left(u_{i}^{M}\right) c_{i+1}^{P}+\frac{\partial^{2} F^{N}}{\partial u^{P} \partial u^{Q}}\left(u_{i}^{M}\right) c_{i+1}^{P} c_{i+1}^{Q}+\ldots=0
$$

A linear system of equations:

$$
K_{i}^{N P} c_{i+1}^{P}-F_{i}^{N}=0
$$

$K_{i}^{N P}$ Is the Jacobian matrix.

The best way to measure the convergence of Newton's method is to ensure that the entries in $F_{i}^{N}$ and the inflows in $c_{i+1}^{M}$ are small enough. (ABAQUS Documentation).

\section{NUMERICAL EXAMPLES OF STIFFENED PANEL}

$\mathrm{W}$

e considered a square panel, where the total length of the panel $a=357 \mathrm{~mm}$ and its width $b=357 \mathrm{~mm}$, with a radius $R=381 \mathrm{~mm}$ and thickness of stiffened composite panels $t_{T}=1 \mathrm{~mm}$ as shown in Fig. 3, the thickness of each layer is $t=0.125 \mathrm{~mm}$, this panel consists of eight layers. The width of the stiffeners $a=33 \mathrm{~mm}$. The layers with orientations are $0, \pm 15, \pm 30, \pm 45, \pm 60, \pm 75, \pm 90$. Epoxy is treated as a matrix material. Tab. 1 shows the mechanical properties of the panels.

The mesh convergence studies using non-linear buckling analyses are corresponded to 5128 shell nodes and 5104 linear quadrilateral elements of type S4R. For the representation of boundary conditions used in this study, let $u, v$ and $w$ be (the translations), while $r_{x}, r_{y}$ and $r_{z}$ are (the rotations) the slender (or roughly) $x, y$ and $z$-axes as shown in Fig. 2. The 
longitudinal (uniform axial compression) edges are simply supported, with $w=0$ and $r_{x}=r_{y}=0$. The transverse (loaded) edges are simply supported; so $w=0$ and $r_{x}=0$, I-shape stiffeners are represented as Fig. 3.

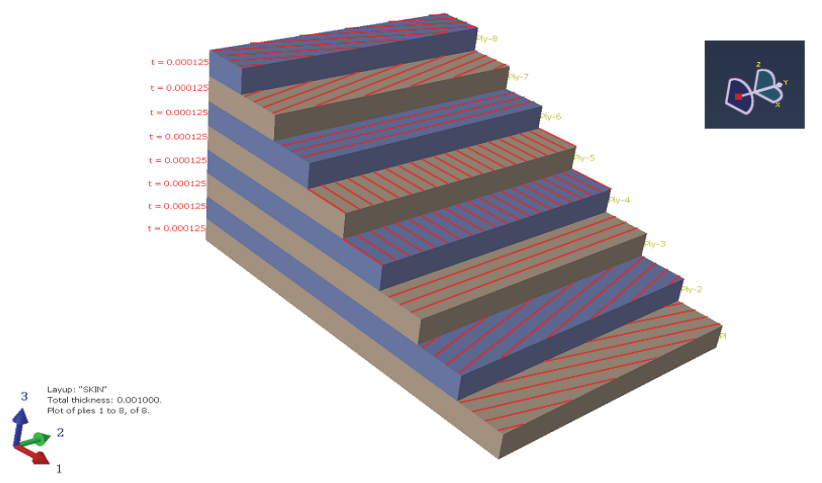

Figure 3: Layup sequence used in the state is 8 layers with total thickness is $1 \mathrm{~mm}$

In the current study, the mechanical properties of the composite materials panels made of different laminas are clearly given in table below:

\begin{tabular}{|c|c|c|c|c|c|}
\hline \multirow[b]{2}{*}{ Quantity } & \multirow[b]{2}{*}{ Symbol } & \multirow{2}{*}{ Units } & \multicolumn{3}{|c|}{ Material } \\
\hline & & & CFC & E-glass & Kevlar \\
\hline Young's modulus $0^{\circ}$ & $E_{11}$ & $G P a$ & 164 & 38 & 195 \\
\hline Young's modulus $90^{\circ}$ & $E_{22}=E_{33}$ & $G P a$ & 12.8 & 8.27 & 14.6 \\
\hline Shear modulus in planes & $G_{12}=G_{13}$ & $G P a$ & 4.5 & 4.14 & 7.5 \\
\hline Shear modulus in planes & $G_{23}$ & $G P a$ & 2.5 & & 5 \\
\hline Poisson's ratio in planes & $v_{12}=v_{13}$ & None & 0.32 & 0.25 & 0.3 \\
\hline Poisson's ratio in planes & $v_{23}$ & None & 0.45 & 0.27 & 0.45 \\
\hline Density & $\rho$ & $\mathrm{Kg} / \mathrm{m}^{3}$ & 1800 & 1900 & 1400 \\
\hline
\end{tabular}

Table 1: Mechanical properties of the CFC, the E-glass and Kevlar used in the analysis [20].

\section{Steps for Nonlinear buckling analysis}

In post-buckling analysis nonlinear load-deflection curve is produced based on the modified Riks algorithm [21].

The shape of nonlinear buckling is induced with an initial defect based on the modes of buckling extracted. The buckling analysis is modified to perform a nonlinear load deflection analysis to predict post-buckling behavior.

The following steps were followed in performing the static nonlinear buckling analysis in Abaqus FEA software.

1. Defined for the composite stiffened panel properties module using a composite layup.

2. The mechanical properties of each lamina are listed in Tab. 1.

3. For nonlinear buckling analysis, the eigenvalue buckling step is a static Riks step.

4. The axial force is defined along with the boundary conditions.

5. The history output query is added to define the displacement history for the loads applied.

6. The boundary conditions are applied and the job is submitted for the static nonlinear buckling analysis, the progress of the solution is monitored.

7. The results of the static nonlinear analysis buckling analysis can be processed. 
The results of the buckling analyses are discussed in detail in Fig. 5. This figure presents the variation of the loads buckling as function displacement with the different layup sequences and combinations of composite material.

\section{Boundary condition of stiffened panel}

The stiffened panel is modeled by the finite element method using S4R elements as shown in Fig. 4. This model consists of I-shaped stiffeners as shown in Fig. 4(a) and 4(b). The panel is completely narrow at the base element, free to move axially along the longitudinal section of the upper edge, and simply along its vertical edges, with an axial compression of $10 k N$ being applied to the stiffened panel.

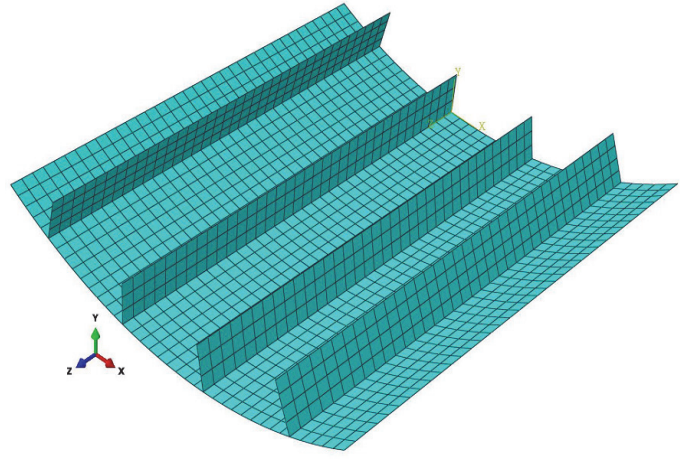

(a)

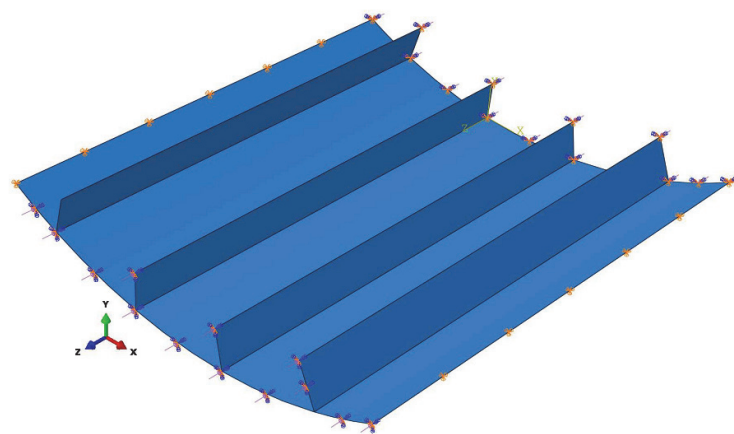

(b)

Figure 4: Finite element models with the straight stiffeners (a) and Finite element model with configuration boundary conditions and loads (b).

\section{COMPARES THE BUCKLING LOADS BY NUMERICAL MODEL AND THE EXPERIMENTAL RESULTS}

7 here is a lookout for the scenario where, the configurations of the composite stiffened panel made of the Kevlar epoxy and the buckling loads of the model analyzed by the finite element method (FEM) are in good agreement with the experimental results, this is a model of the experiment carried out in laboratory National School of Arts \& Crafts in Meknes -Morocco, where they studied the buckling stresses and buckling loads with different configurations of the composite stiffened panel. Their results presented estimates for three sequences; including linear Eigenvalue analysis loads (pre-buckling) of the numerical model in ABAQUS, which when compared with existing studies, are excellent. However, this found the best results using the static non-linear buckling analysis method. This nonlinear method (NM) for the numerical solution was found to be in very close agreement with the experiment results, which is better than the method used by Sudhir Sastry Y.B et al. [18].

\section{Analysis of the stiffened panel with four I stiffeners}

In this work, we studied the nonlinear buckling analysis of the composite stiffened panel with four stiffeners, as shown in the Fig. 4(a). We eventually considered several cases which are generated by lay-up variation and decided to take the different combinations of materials for all configuration of the composite stiffened panel. In this example, we examined several orientations with layup sequences $(45 /-45 / 90 / 0)_{s},(90 / 0 / 90 / 0)_{s}$ and $(60 /-30 / 90 / 0)_{s}$, respectively. We have examined several combinations of materials for stiffened panels; the cases analyzed in this work are shown below: when the panel and the stiffeners are made of the same material, the carbon fiber composite (CFC) for panel and stiffeners, E-glass (EG) for panel and stiffeners, Kevlar for panel and stiffeners, as shown in Fig. 6 (a, b and c).

We examined the first case in Fig. 6(a) and 6(b) with a layup sequence $(45 /-45 / 90 / 0)_{s}$, the stiffeners and the skin are of the same configuration with respect to the composite material. We have noticed that, when the panel and stiffeners are made of Kevlar material, it has a maximum critical load, with a static non-linear buckling $P_{r r}=84 \mathrm{kN}$, of E-glass composite, the epoxy contains the minimum critical buckling loads $P_{a r}=22 \mathrm{kN}$, and, when carbon fiber composite (CFC) is placed in the middle of Kevlar and E-glass as shown in Fig. 6(a), the critical load $P_{c r}=68 \mathrm{kN}$. However, when the panel is made of different materials, for instance, the critical load of maximum buckling is observed when the panel is made of 
Kevlar skin and CFC stiffeners whereas, the critical load of the minimum buckling is observed in the E-glass skin with CFC stiffeners, as shown in Fig. 6(b).

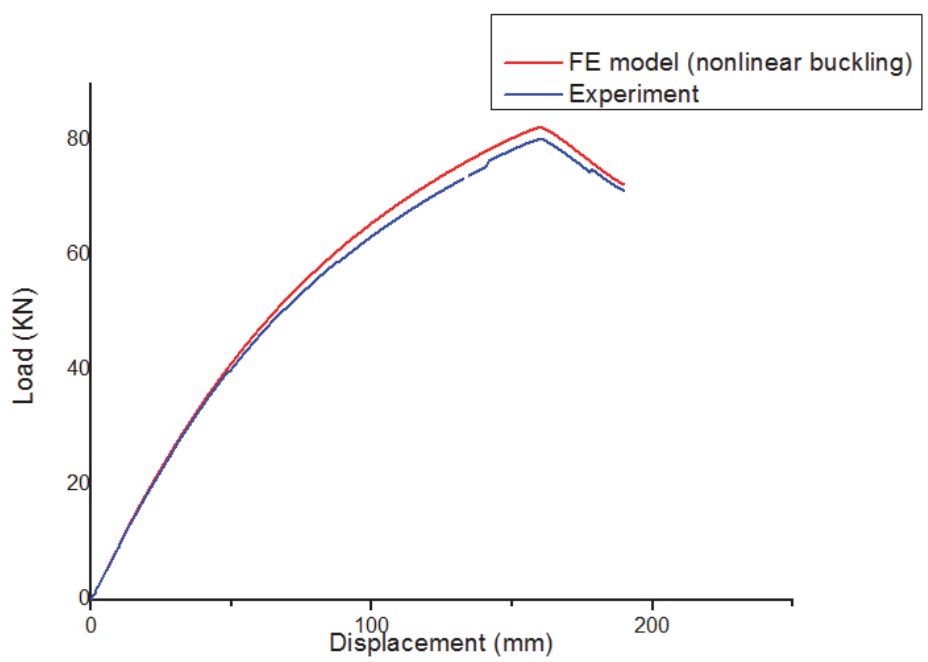

Figure 5: Comparison of nonlinear buckling loads from finite element model and the experimental model. When a constant load is applied to different materials of Layup sequence (45/-45/90/0) s.

In case number two, we examined a Layup sequence $(90 / 0 / 90 / 0)_{s}$, where the stiffeners and the skin are made of the same composite material and this panel holds the four stiffeners, critical buckling loads are plotted in the Fig. 6(c) and (d), respectively.

We looked at a condition, where the skin and the stiffeners are of the same composite material, given Kevlar for instance, it has a maximum critical buckling load, E-glass epoxy have the minimum load, the critical loads of the non-linear static buckling of the CFC is placed between the Kevlar and EG, as shown in the curves Fig. 6(c). And when the skin and stiffener are made of different composite materials, the maximum critical loads are observed for composite in Kevlar skin and CFC stiffener, while the minimum loads are observed in composites with EG skin and CFC stiffener as shown in Fig. 6(d).

A layup sequence (60/-30/90/0)s; we have observed that when the skin and stiffeners are made of the same composite material, Kevlar is the most resistant-glass epoxy known for minimum loads and the lowest loads, while CFC is placed in the middle, as shown in Fig. 6(e).

When the skin and the stiffener are made of different composite materials, maximum loads are observed in epoxy Kevlar skin with CFC stiffeners, while the minimum load is observed when the composite materials are EG skin and CFC stiffeners. Considering the most severe of the composite stiffened panel configuration with regards to buckling strength along with the different composite materials.

The stress distribution at different composite materials and ply orientations are shown in Fig. 7(a)-(f).

The stress distribution of different configurations is plotted in Fig. $7(\mathrm{a}-\mathrm{f})$. The nonlinear analyses is performed and VonMises stress is calculated around the stiffened panel composite, with different composite materials and ply sequence.

The von Mises stress distribution at different combinations of composites and ply orientations view are shown in Fig. 7. The maximum von Mises stress is $354.4 \mathrm{MPa}$ on the case Layup sequence (45/-45/90/0) s with composites EG skin and $\mathrm{CFC}$ stiffener, which is in red color in Fig. 3. The second higher von Mises stress is $175.3 \mathrm{MPa}$ occurs in Layup sequence (90/0/90/0) s with composites EG skin and CFC stiffener, the low von Mises stress values, below $47.78 \mathrm{MPa}$. The maximum von Mises stress in the stringer and near the edge of the loading.

The von Mises stresses obtained with various materials and different ply orientation ((45/-45/90/0)s, (60/-30/90/0)s and $(90 / 0 / 90 / 0)$ s) are plotted on the graph shown in Fig.8, The results of the simulations also made it possible to identify the most unfavorable, that is to say, the one for which the critical stress is the lowest. It corresponds to the combinations with ply orientation (90/0/90/0)s and Composites with EG skin and EG stiffener, the maximum von Mises stress with ply orientation (45/-45/90/0)s and Composites with EG skin and CFC stiffener. 


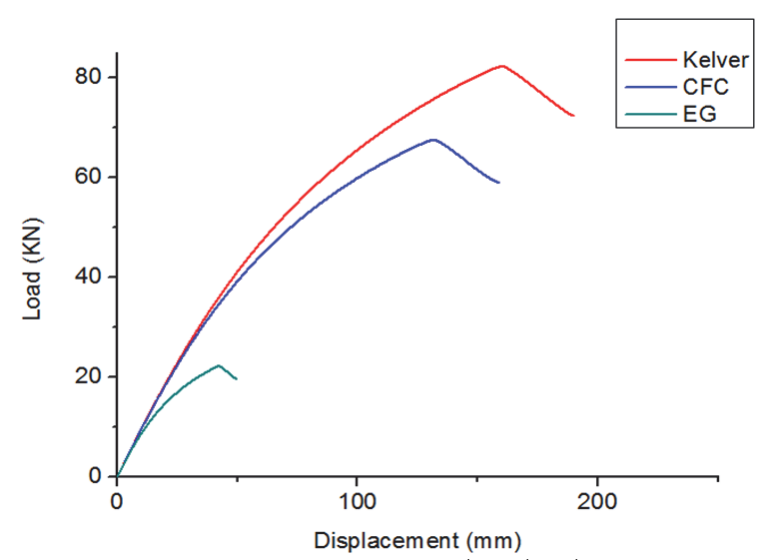

(a) Layup sequence $(45 /-45 / 90 / 0) \mathrm{s}$

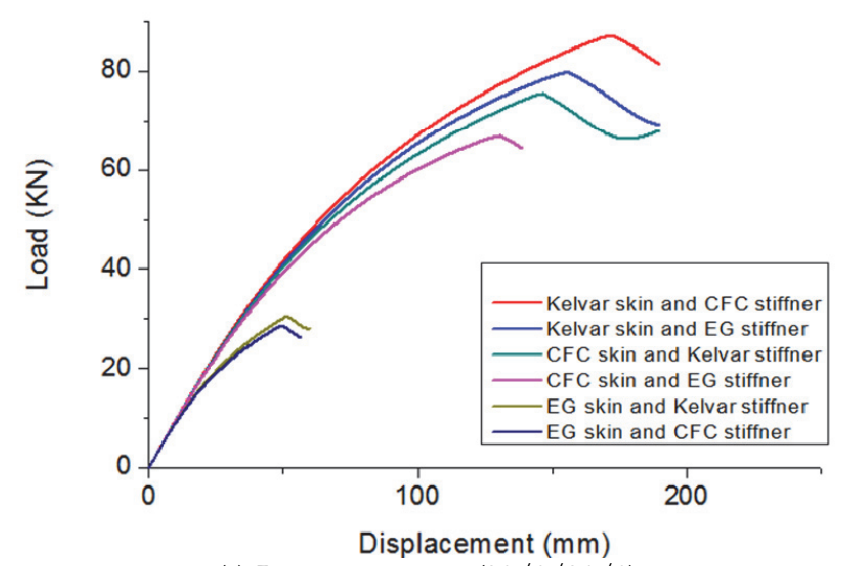

(c) Layup sequence $(90 / 0 / 90 / 0) \mathrm{s}$

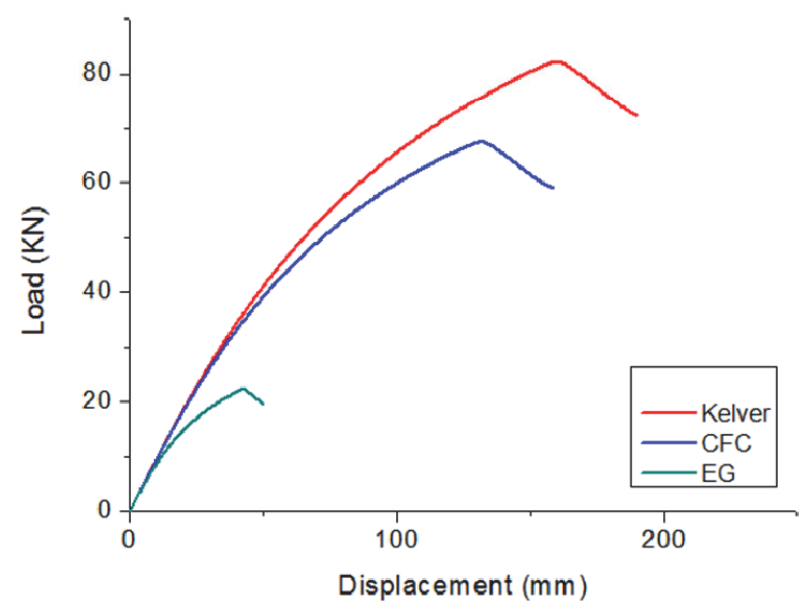

(e) Layup sequence $(60 /-30 / 90 / 0) \mathrm{s}$

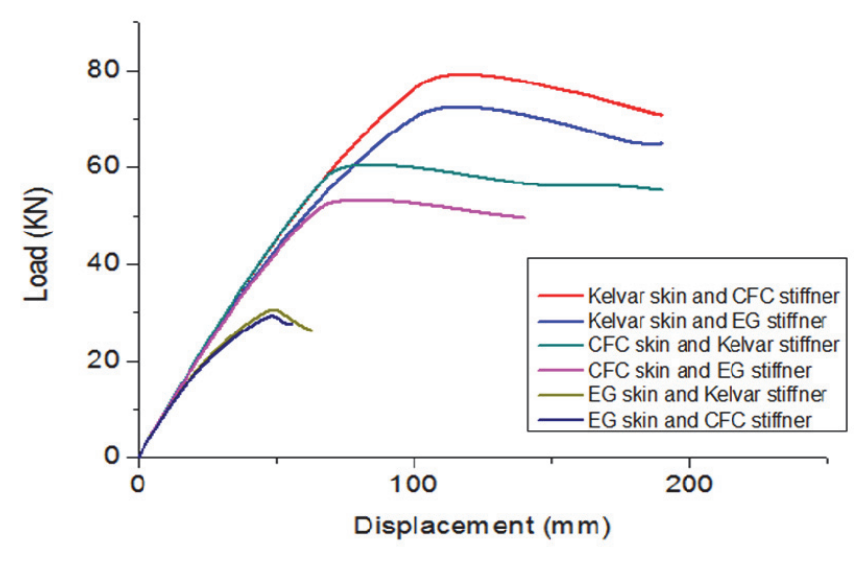

(b) Layup sequence $(45 /-45 / 90 / 0) \mathrm{s}$

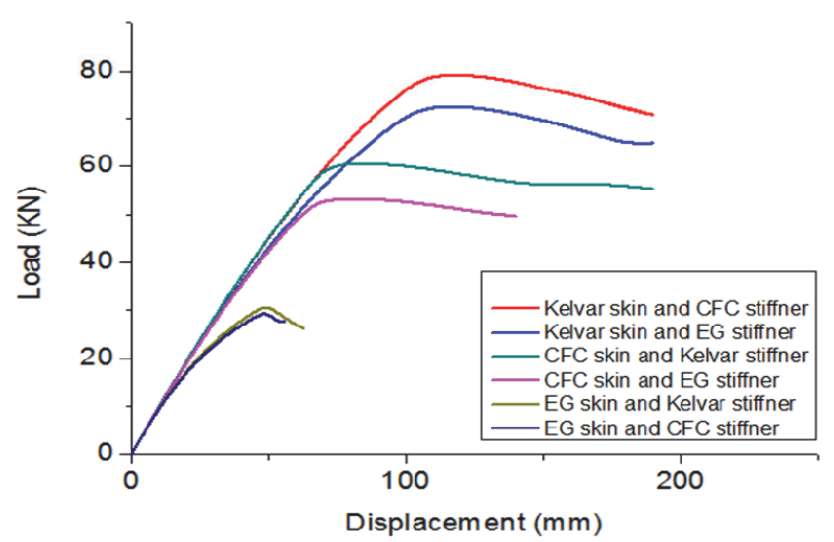

(d) Layup sequence $(90 / 0 / 90 / 0)$ s

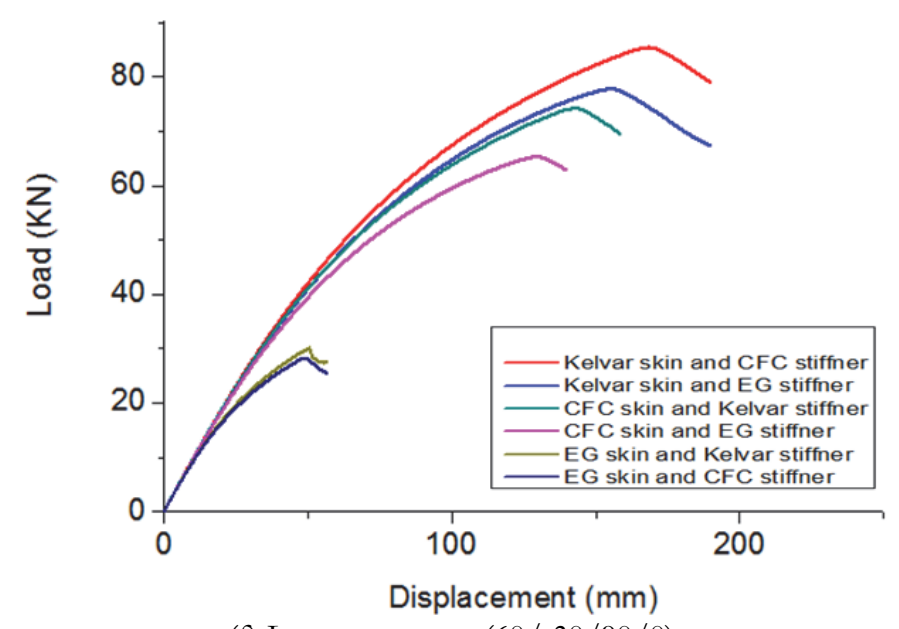

(f) Layup sequence $(60 /-30 / 90 / 0) \mathrm{s}$

Figure 6: Variation of the loads buckling as function displacement with the different layup sequences and combinations of composite material. 


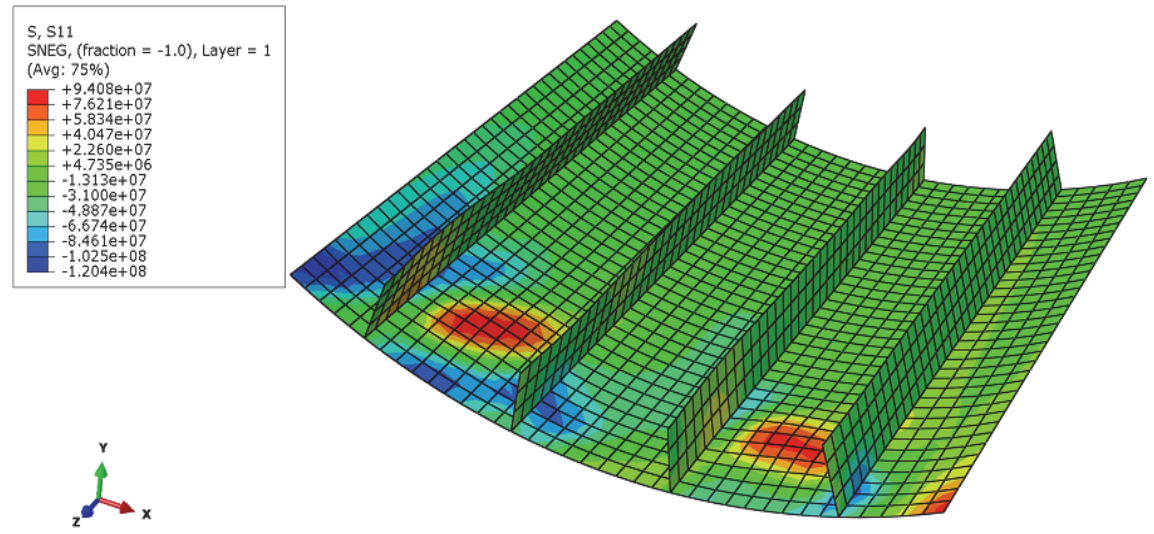

(a) Von-Mises stress with a Layup sequence (45/-45/90/0) s; The stiffeners and the skin are of the same configuration (E-glass (EG))
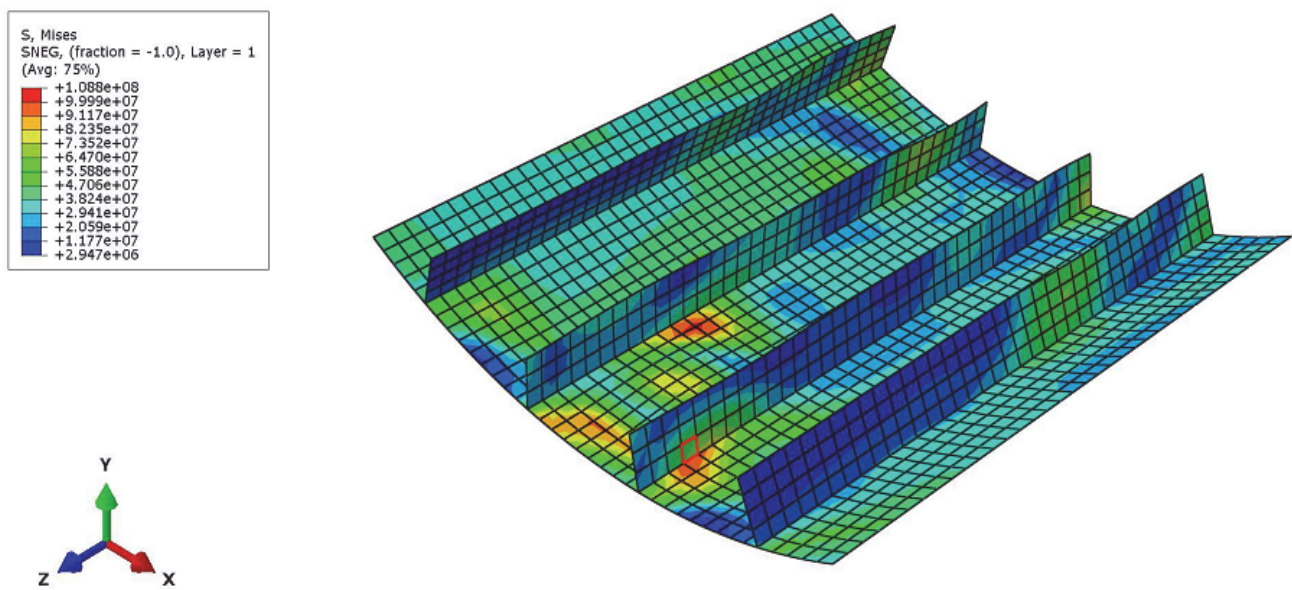

(b) Von-Mises stress with a Layup sequence (60/-30/90/0)s; The stiffeners and the skin are of the same configuration (E-glass (EG))
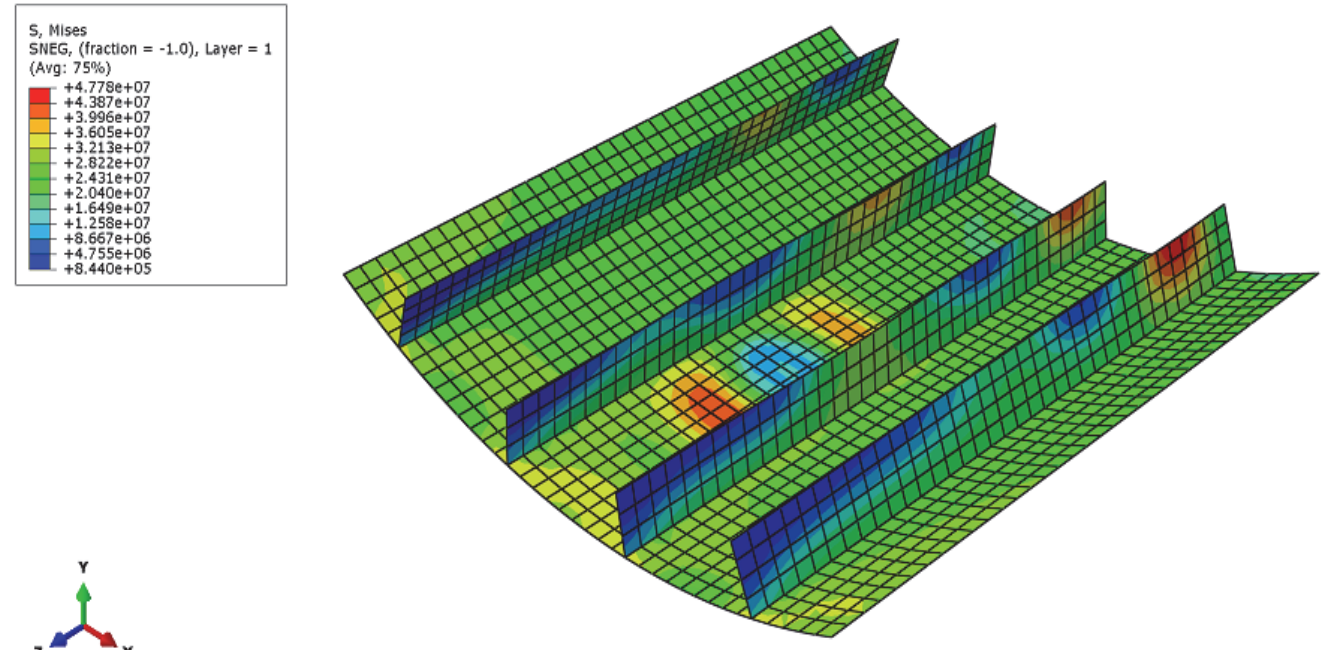

(c) Von-Mises stress with a Layup sequence $(90 / 0 / 90 / 0)$ s; The stiffeners and the skin are of the same configuration (E-glass (EG)) 

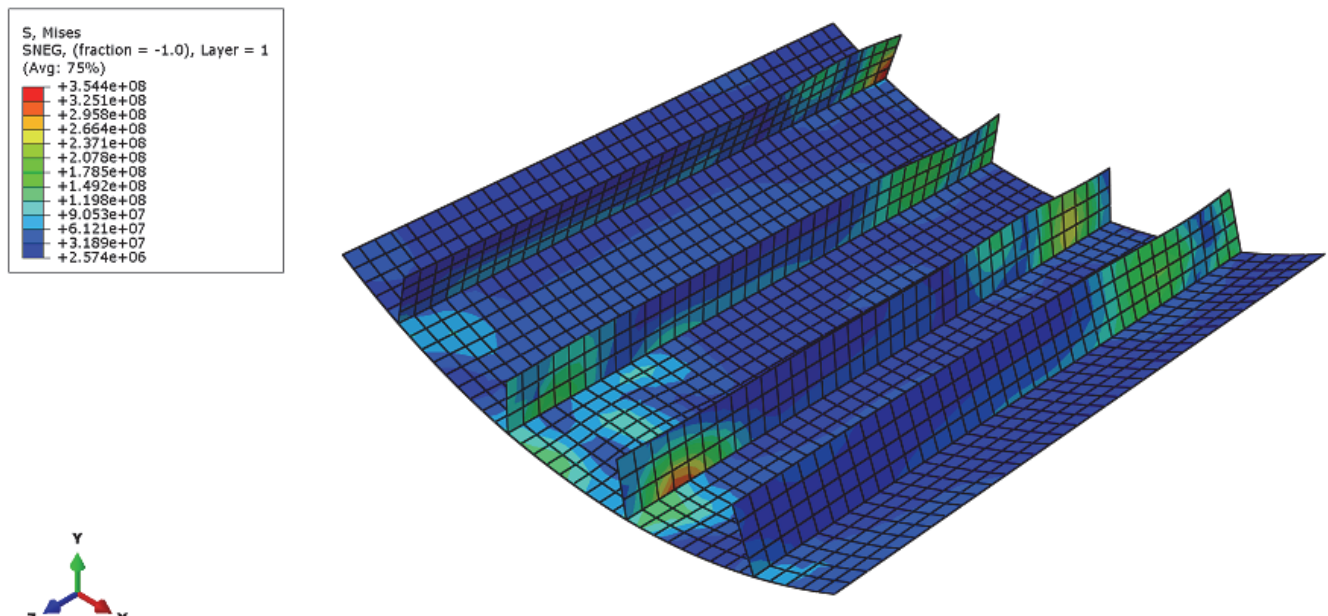

(d) Von-Mises stress with a Layup sequence (45/-45/90/0) s; Composites with EG skin and CFC stiffener
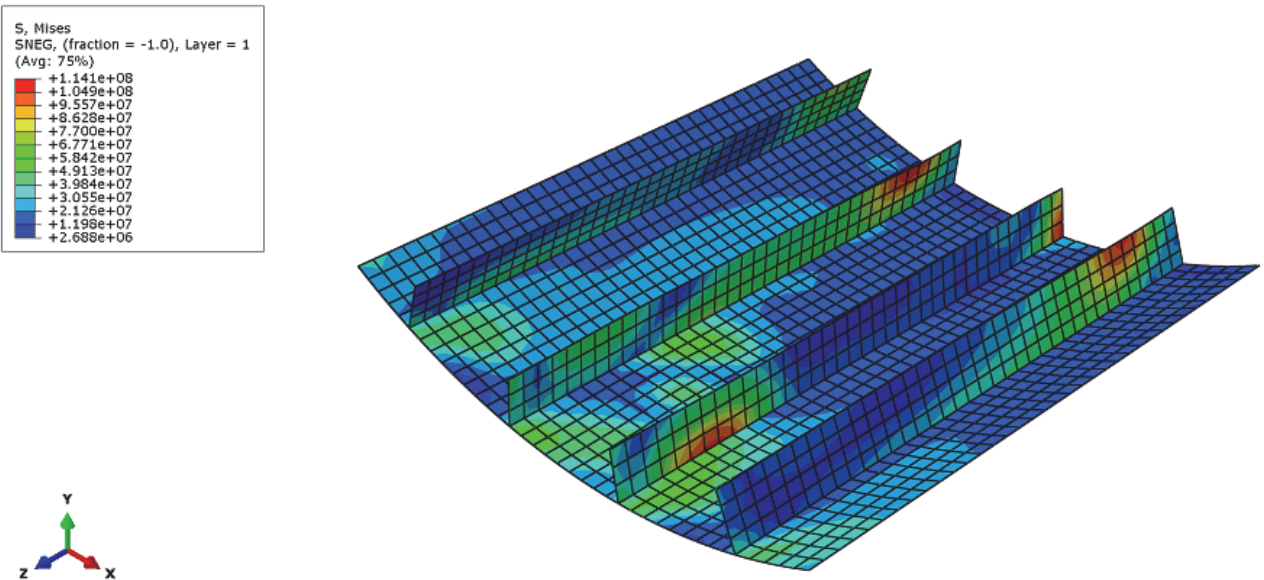

(e) Von-Mises stress with a Layup sequence (60/-30/90/0) s; Composites with EG skin and CFC stiffener
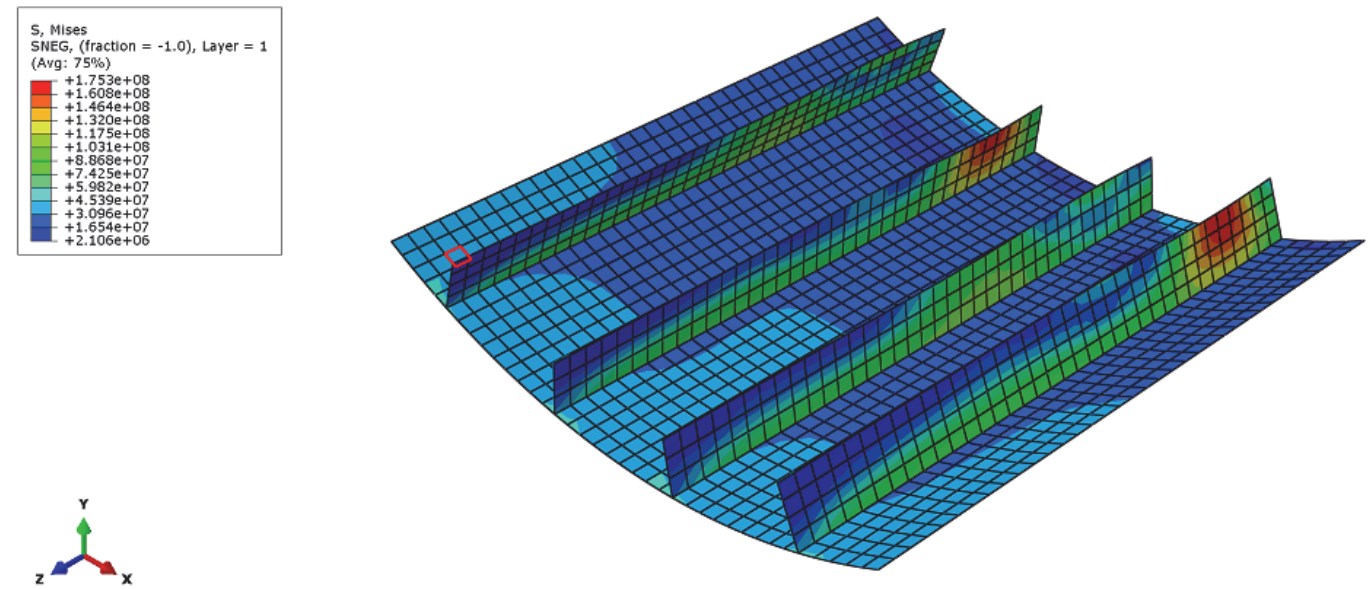

(f) Von-Mises stress with a Layup sequence (90/0/90/0) s; Composites with EG skin and CFC stiffener

Figure 7: The Von-mises stresses at different composite materials and ply orientations of the panel with 4 Straight stiffeners. 


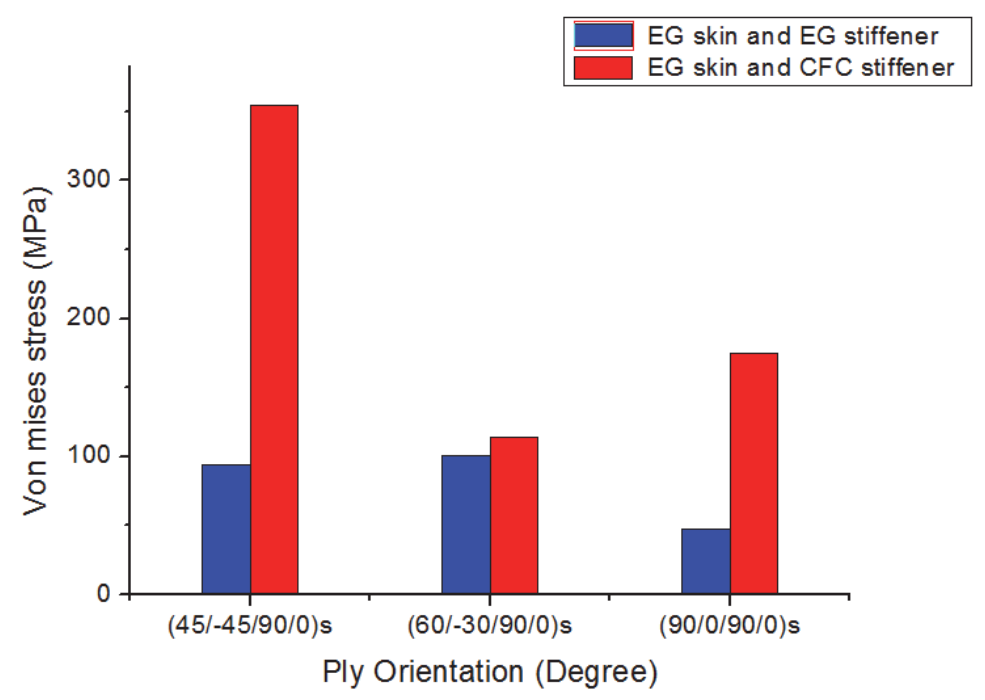

Figure 8: Von Mises stresses obtained for the various ply layout sequences.

\section{CONCLUSION}

A ccording to the study of the three previous cases, we observed that when the skin and the stiffener are made of the Kevlar, the panel has better resistance compared with the other studied composites. The ply sequence (60/30/90/0)S has the maximum critical buckling load. When the panel and the stiffener contain different composites, the Kevlar skin and the CFC stiffener has a maximum buckling load with orientation (45/-45/90/0)S. After this work, we would like to study complex aircraft structures with both material and geometric imperfections and validate finite element models through experiments.

The next work we want to extend the current techniques to complicated structures like the airplane wing and validate the FE results with practice. We will consider a stiffened panel composite with having local geometric and material imperfections and to evaluate the effects of damage in composite stiffened panel using lamb wave propagation.

\section{ACKNOWLEDGEMENTS}

7 his work is sponsored by Structure LGCE ,EST Sale -CED of Mohammadia Engineering School Mohammed V University, Rabat. These supports are gratefully acknowledged. The authors also wish to thank the anonymous reviewers for their thorough review of the article and their constructive advice.

\section{REFERENCES}

[1] Abramovich, H., Weller, T. (2005). Buckling until collapse of a damaged panel. COOCMAT - Technion. Technical Report, Tel Aviv.

[2] Degenhard, R., Rolfes, R., Zimmerman, R., (2006). Improved material exploitation of composite airframe structures by accurate simulation of post-buckling and collapse. Composite Structures (73), pp. 175-178. DOI: 10.1.1.567.5341.

[3] Zimmermann, R., Rolfes, R. (2006). POSICOSS - Improved post-buckling simulation for design of fibre composite stiffened fuselage structures. Composite Structures (73), pp. 171-174. DOI: 10.1016/j.compstruct.2005.11.041.

[4] Ravi, B., Deo, James, H., Starnes, Jr., Holzwarth, R.C. (2001). Low-Cost Composite Materials and Structures for Aircraft Applications.RTO AVT Specialists' Meeting on “Low Cost Composite Structures", Loen, Norway, published in RTO-MP-069(II).

[5] Budarapu, P.R., Sudhir, Y.B., Javvaji, B., Mahapatra, D.R. (2014). Vibration Analysis of Multi-walled Carbon Nanotubes Embedded in Elastic Medium. Frontiers of Structural and Civil Engineering, 8(2), pp. 151-159. 
DOI: $10.1007 /$ s11709-014-0247-9.

[6] Kachanov, L.M. (1988). Delamination Buckling of Composite Materials, Kluwer Academic Publishers, Dordrecht (The Netherlands).

[7] Wright, J. E. (2006). Compound bifurcations in the buckling of a delaminated. Composite structure. Nonlinear Dynamic 43(1-2), pp. 59-72. DOI: 10.1007/s11071-006-0751-0.

[8] Short, G., Guild, F. J., Pavier, M. J. (2002). Delamination in flat and curved composite laminates subjected to compressive load. Composite Structure, 58(2), pp. 249-258. DOI: 10.1016/S0263-8223(02)00052-1.

[9] Hunt, G. W., Butler, B., Almond, D. P., Wright, J. E. (2004). Nonlinear modeling of delaminated structures. AIAA J 42(11), pp. 2364-2372. DOI: 10.2514/1.5981.

[10] Mallela, U. K., Upadhyay (2006). Buckling of laminated composite stiffened panels subjected to in-plane shear: a parametric study. Thin-Walled Structures, 44(3), pp. 354-361. DOI: 10.1016/j.tws.2006.03.008.

[11] Kistler, L. S., Waas, A. M. (1998). Experiment and analysis on the response of curved laminated composite panels subjected to low velocity. Journal of Impact Engineering, 21(9), pp. 711-736. DOI:10.1016/S0734-743X(98)00026-8.

[12] Singh, S. B., Kumar, D. (2008). Post-buckling response and failure of symmetric laminated plates with rectangular cutouts under uniaxial compression. Structural Engineering and Mechanics 29(2), pp. 455-467. DOI:10.12989/sem.1997.5.4.433.

[13] Zhang, Y., Rheeb, K. Y., Parka, S.-J. (2017). Nanodiamond nanocluster-decorated grapheme oxide/epoxy Nano composites with enhanced mechanical behavior and thermal stability. Composites Part B: Engineering, 114, pp. 111120. DOI:10.1016/j.compositesb.2017.01.051.

[14] Gal, E., Levy, R., Abramovich, H., Pavsner, P. Buckling analysis of composite panels. (2006). Composite structure, 73(2), pp.179-185. DOI: 10.1016/j.compstruct.2005.11.052.

[15] Kim, Y. H., Noor, A. K. (1996). Buckling and post-buckling of composite panels with cutouts subjected to combined loads, Finite Elements in Analysis and Design, 22(2), pp. 163-185. DOI: 10.1016/0168-874X (95)00052-U.

[16] Leissa, A.W. (1987). Review of laminated composite plate buckling. ASME Appl. Mech. Rev., 40 (5), pp. 575-591. DOI: $10.1115 / 1.3149534$.

[17] Broekel,J., Prusty,G. (2004).Experimental and theoretical investigations on stiffened and unstiffened composite panels under uniform transverse loading. Composite Structure, 63, pp. 293-304. DOI: 10.1016/S0263-8223(03)00178-8.

[18] SudhirSastry, Y. B., Pattabhi, R., Madhavi, N., Krishna, Y. (2015). Buckling analysis of thin wall stiffened composite panels. Computational Materials Science. 96, pp. 459-471. DOI: 10.1016/j.commatsci.2014.06.007.

[19] L. A. (1995). Finite elements for post-buckling analysis. II -Application to composite plate assemblies, Computer Structure, 56 (6), pp. 1019-1028. DOI:10.1016/0045-7949(94)00573-L.

[20] Reddy, J. N. (1997). Mechanics of laminated composite plates. CRC Press. New York.

[21] Riks, E. (1979). An incremental approach to the solution of snapping and buckling problems, International Journal Solids Structures, 15, pp. 524-551. DOI: 10.1016/0020-7683(79)90081-7.

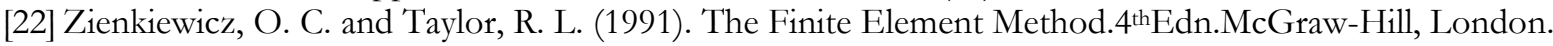

